\title{
Direct medical charges of pediatric traumatic brain injury in multiple clinical settings
}

\author{
Christy L Collins ${ }^{1}$, Keith Owen Yeates ${ }^{2,3}$, Thomas L Pommering ${ }^{4,5}$, Rebecca Andridge ${ }^{6}$, Victor G Coronado ${ }^{7}$,
} Julie Gilchrist ${ }^{7}$ and R Dawn Comstock ${ }^{*^{*}}$

\begin{abstract}
Background: Data limited to emergency department and inpatient visits undoubtedly underestimate the medical charges associated with traumatic brain injury. The objective of this study was to estimate the direct medical charges of pediatric traumatic brain injuries across all clinical settings in one large, pediatric hospital in the United States.
\end{abstract}

Methods: Traumatic brain injuries sustained by children $\leq 20$ years of age treated across all clinical settings at one large pediatric hospital from August 1, 2010-July 31, 2011 were identified using ICD-9-CM codes 310.2, 800-801.9, 803-804.9, 850-854.16, and 959.01.

Results: 3,971 individuals $\leq 20$ years of age were seen during 5,429 traumatic brain injury-related visits. Total medical charges for pediatric traumatic brain injury-related visits were $\$ 13,131,547$. Inpatient (68.7\%) and emergency department (16.1\%) visits accounted for the highest proportion of TBI-related charges; however, $>15 \%$ of all charges were associated with visits to clinic outpatient, urgent care, and diagnostic/therapy outpatient settings. Fracture of the vault or base of the skull (37.1\%) and brain injury with contusion, laceration, or hemorrhage (27.1\%) accounted for the largest proportion of total charges. Although unspecified head injuries made up almost half of all TBI-related visits (47.4\%), they accounted for only $12.6 \%$ of total charges. Mild traumatic brain injuries accounted for $92.0 \%$ of all traumatic brain injury-related visits but only $44.7 \%$ of all traumatic brain injury-related charges. Mild traumatic brain injuries treated in the emergency department had a higher median total charge than those treated in urgent care $(p<0.0001)$ or clinic outpatient setting $(p<0.001)$.

Conclusions: This study, the first to evaluate the direct medical charges of pediatric traumatic brain injury across all clinical settings at one large pediatric hospital, found that pediatric traumatic brain injuries present to a wide variety of clinical settings, and differences exist in total charges by diagnosis, severity of the injury, and clinical site/setting. Investigating traumatic brain injuries across the full spectrum of clinical care is needed for a better understanding of the true medical cost and public health burden of pediatric traumatic brain injury.

Keywords: Traumatic brain injury; Children; Medical charges

\section{Background}

Traumatic brain injury (TBI) has received increasing attention over the past decade because of its incidence, economic cost, human impact, and preventability. Although the true incidence of TBI is unknown, in 2009 in the United States (US), there were at least 2.4 million emergency department (ED) visits, hospitalizations, and deaths

\footnotetext{
* Correspondence: dawn.comstock@ucdenver.edu

${ }^{8}$ Colorado School of Public Health, Epidemiology and Pediatric Injury Prevention, Education, and Research (PIPER) Program, Aurora, CO, USA Full list of author information is available at the end of the article
}

related to a TBI, either alone or in combination with other injuries (Coronado et al. 2012a). As TBIs can have both short and long term effects including impairment of physical, cognitive, or emotional functions, (National Center for Injury Prevention and Control 2003; Cassidy et al. 2004) many TBI prevention recommendations have been made; yet, the reported incidence of TBI continues to increase (Faul et al. 2010; Thurman et al. 1999; National Center for Injury Prevention and Control 2003).

Estimated in 2009 US dollars, the total lifetime health care cost of fatal, hospitalized, and non-hospitalized TBI

\section{实}

(c) 2014 Collins et al.; licensee Springer. This is an Open Access article distributed under the terms of the Creative Commons Attribution License (http://creativecommons.org/licenses/by/2.0), which permits unrestricted use, distribution, and reproduction in any medium, provided the original work is properly credited. 
was approximately $\$ 221$ billion. Of this, $\$ 57.8$ billion were related to hospitalization-related costs (Orman et al. 2011). Mild TBIs (mTBI), which may account for 70\%-90\% of all TBIs, (Faul et al. 2010; Cassidy et al. 2004) often present to clinical settings other than the ED (e.g., urgent care clinics, sports medicine clinics, concussion clinics, etc.) (Schootman and Fuortes 2000; National Center for Injury Prevention and Control 2003; Cassidy et al. 2004; McCrea et al. 2004; Kirkwood et al. 2008; Thurman et al. 1999). Therefore, not only has the incidence of TBI been underestimated, but the resultant cost of TBI has certainly been underestimated as well.

Pediatric TBIs, including mTBIs, are of special concern. Children $<14$ years of age account for nearly half a million $(473,947)$ TBI-related ED visits in the US annually, (Faul et al. 2010) and the highest rates of TBI-related ED visits occur among children $<5$ years and adolescents 15 to 19 years of age (Faul et al. 2010). Like adults, children who sustain TBIs are at risk of short term physical, cognitive, emotional, and social impairments (Moran et al. 2012; Taylor 2004; Yeates et al. 2012). Additionally, TBI may continue to negatively affect development and brain maturation as children grow into adulthood (Anderson et al. 2004) (Yeates et al. 2005; Schwartz et al. 2003).

Several studies have investigated the economic burden of pediatric TBI; however, the definition of "cost" has varied widely across these studies (Rockhill et al. 2010; Schneier et al. 2006; Shi et al. 2009; Jaffe et al. 1993; Brener et al. 2004). One study from 2006 found pediatric TBI-related hospitalization charges in the US totaled approximately $\$ 2.6$ billion dollars (Shi et al. 2009). Again, this figure underestimates the true cost of pediatric TBI as data were utilized from only one clinical setting (i.e., inpatient data) (Schneier et al. 2006; Shi et al. 2009). Another study that included pediatric TBI-related direct and indirect costs from various clinical settings found, from 1997 through 2000, the cost of mild to moderate pediatric TBI-related services totaled $\$ 77.9$ million annually in the US (Brener et al. 2004). However, the generalizability of previous studies that used cost data from multiple clinical settings may be limited as they included a relatively small sample of children (Brener et al. 2004; Jaffe et al. 1993). The objective of this study was to evaluate the true direct medical charges of pediatric traumatic brain injuries by analyzing total medical charges across multiple clinical settings at one large United States (US) Midwest Children's Hospital.

\section{Methods}

TBIs from all causes sustained by children $\leq 20$ years of age treated at one large Midwest Children's Hospital from August 1, 2010 through July 31, 2011 were identified using ICD-9-CM codes 310.2, 800-801.9, 803-804.9, 850-854.16, and 959.01 as the principal diagnosis. Previous studies have found that sports-related activities account for a large proportion of pediatric TBIs; (Leibson et al. 2011; Meehan and Mannix 2010) therefore, an academic year time period was used in an effort to capture sports-related initial injury visits as well as any related follow-up visits in our study period. We captured all TBIs seen across the wide array of clinical settings at this Children's Hospital including inpatient, ED, urgent care, clinic outpatient, and diagnostic/therapy outpatient settings.

Variables of interest included sex, age of patient at first visit, race (white, Black/African American, two or more races, other, and unknown), zip code from patient's home address, clinical site/setting (inpatient, ED, urgent care, clinic outpatient, diagnostic/therapy outpatient, observation, and organ procurement), principal diagnosis, primary payor (commercial, Medicaid, self-pay, and other), and total medical charges. Data from the US Census Bureau were used to obtain average median household income of the zip codes from the patients' home address (patient zip code and/or median household income were missing for 12 individuals). Individual ICD-9-CM codes were grouped into 5 diagnosis categories: 1) concussion (ICD-9-CM codes 850.0-850.9 and 310.2), 2) head injury, unspecified (959.01), 3) brain injury with contusion, laceration, or hemorrhage (851.0-854.16), 4) fracture of the vault or base of the skull (800.0-801.9), and 5) other and unqualified multiple fractures of the skull (803.0-804.9). Based on criteria from past research, (Bazarian et al. 2006) the following ICD-9-CM codes meet the CDC criteria for a case of mild TBI:

\begin{tabular}{ll}
\hline ICD-9-CM First Four Digits & ICD-9-CM-Fifth Digit \\
800.0, 800.5, 801.0, 801.5, 803.0, 803.5, & $0,1,2,6,9$, Missing \\
$804.0,804.5,850.0,850.1,850.5,850.9$ & \\
854.0 & $1,2,6,9$, Missing \\
959.0 & 1 \\
\hline
\end{tabular}

Data for mTBI are not shown in all tables but, rather, are largely presented in the text. Total medical charges included all direct charges such as physician charges, pharmaceutical charges, laboratory charges, facility charges, etc.

If an individual had two or more TBI visits during the study period that were more than 90 days apart, two clinicians from the research team (KOY and TLP) independently reviewed the medical records to determine if the visits were related to the same injury event or if they represented multiple independent injury events. The two clinicians reviewed the medical records of 77 individuals with two or more TBI visits and agreed that for 30 individuals the visits were related to the same injury while for 43 individuals the visits represented multiple independent injury events. Medical records were reviewed a 
second time by both clinicians for the 4 (5.2\%) individuals on which they initially disagreed, and an agreement was reached that 1 individual had two or more visits related to the same injury and 3 had two or more visits representing multiple independent injury events.

Data were analyzed using SPSS software, version 19.0. Because average total charge per patient was right-skewed, median total charge per patient was used. Differences in the median total charge per patient by gender were evaluated by a Mann Whitney U test. Differences in total charge per patient by race and primary payor were evaluated by a Kruskal-Wallis test. Linear regression was used to assess total charge per patient by age of the patient at the first visit, average median household income for the patient's zip code, and number of visits per patient. This study was approved by the Institutional Review Board at Nationwide Children's Hospital.

\section{Results}

TBI patients demographics and charges

From August 1, 2010 through July 31, 2011, 3,971 patients $\leq 20$ years of age were seen for a TBI injury at one large Midwest Children's Hospital. The mean age of patients was 7.77 years (SD: 5.88 years), and $61.9 \%$ were male (Table 1 ).

Table 1 Demographic characteristics of pediatric patients with a principal diagnosis of traumatic brain injury at one midwest children's hospital from August 1, 2010 through July 31, 2011, overall and by number of visits per individual

\begin{tabular}{|c|c|c|c|c|}
\hline & \multirow[t]{2}{*}{ Total \# individuals (\%) } & \multirow{2}{*}{$\begin{array}{l}\text { \# Individuals with one } \\
\text { visit* (\%) }\end{array}$} & \multicolumn{2}{|c|}{ \# Individuals with two or more visits* (\%) } \\
\hline & & & $\begin{array}{l}\text { Two or more } \\
\text { related visits }\end{array}$ & $\begin{array}{l}\text { Two or more } \\
\text { unrelated visits }\end{array}$ \\
\hline \multicolumn{5}{|l|}{ Gender } \\
\hline Male & $2,459(61.9 \%)$ & $1,944(61.0 \%)$ & $485(65.5 \%)$ & $30(65.2 \%)$ \\
\hline Female & $1,512(38.1 \%)$ & $1,241(39.0 \%)$ & $255(34.5 \%)$ & $16(34.8 \%)$ \\
\hline Total & $3,971(100.0 \%)$ & $3,185(100.0 \%)$ & $740(100.0 \%)$ & $46(100.0 \%)$ \\
\hline \multicolumn{5}{|l|}{ Age, years } \\
\hline Mean (SD) & $7.77(5.88)$ & $6.93(5.66)$ & $11.39(5.41)$ & $7.04(6.12)$ \\
\hline \multicolumn{5}{|l|}{ Race } \\
\hline White & $2,543(64.0 \%)$ & $1,961(61.6 \%)$ & $551(74.5 \%)$ & $30(65.2 \%)$ \\
\hline Black/African American & $875(22.0 \%)$ & $757(23.8 \%)$ & $110(14.9 \%)$ & $8(17.4 \%)$ \\
\hline Other & $236(5.9 \%)$ & $204(6.4 \%)$ & $29(3.9 \%)$ & $3(6.5 \%)$ \\
\hline Two or more races & $175(4.4 \%)$ & $143(4.5 \%)$ & $27(3.6 \%)$ & $5(10.9 \%)$ \\
\hline Unknown & $143(3.6 \%)$ & $120(3.8 \%)$ & $23(3.1 \%)$ & $0(0.0 \%)$ \\
\hline Total & $3,971(100.0 \%)^{*}$ & $3,185(100.0 \%)^{*}$ & 740 (100.0\%) & 46 (100.0\%) \\
\hline \multicolumn{5}{|l|}{ Primary Payor } \\
\hline Commercial & 2,081 (52.4\%) & 1,552 (48.7\%) & $507(68.5 \%)$ & $22(47.8 \%)$ \\
\hline Medicaid & 1,715 (43.2\%) & 1,487 (46.7\%) & $205(27.7 \%)$ & $23(50.0 \%)$ \\
\hline Self-pay & $126(3.2 \%)$ & 105 (3.3\%) & $21(2.8 \%)$ & $0(0.0 \%)$ \\
\hline Other & $49(1.2 \%)$ & $41(1.3 \%)$ & $7(0.9 \%)$ & $1(2.2 \%)$ \\
\hline Total & 3,971 (100.0\%) & 3,185 (100.0\%) & $740(100.0 \%)^{*}$ & $46(100.0 \%)$ \\
\hline \multicolumn{5}{|c|}{$\begin{array}{l}\text { Average median household } \\
\text { income by patient zip code, } \\
\text { dollars }\end{array}$} \\
\hline Mean (SD) & $56,242(22,797)$ & $55,167(22,519)$ & $60,986(23,350)$ & $54,551(23,759)$ \\
\hline $\begin{array}{l}\text { Total charges per } \\
\text { patient, dollars }\end{array}$ & $\begin{array}{l}\text { Total charge per } \\
\text { patient }\end{array}$ & $\begin{array}{l}\text { Total charge per patient } \\
\text { among individuals with } \\
\text { one visit }\end{array}$ & $\begin{array}{l}\text { Total charge per patient } \\
\text { among individuals with two } \\
\text { or more related visits }\end{array}$ & $\begin{array}{l}\text { Total charge per patient } \\
\text { among individuals with two } \\
\text { or more unrelated visits }\end{array}$ \\
\hline Mean (SD) & $3,307(26,225)$ & $1,832.55(11,129.20)$ & $9,757(55,765)$ & $1,629(1,993)$ \\
\hline Range & $1,016,317$ & 359,606 & $1,016,317$ & 11,217 \\
\hline $25^{\text {th }}$ percentile & 186 & 167 & 701 & 484 \\
\hline $50^{\text {th }}$ percentile & 348 & 320 & 1,254 & 878 \\
\hline $75^{\text {th }}$ percentile & 1,057 & 728 & 2,987 & 2,617 \\
\hline
\end{tabular}

* Totals do not sum to $100.0 \%$ due to rounding. 
The majority of patients were white $(64.0 \%), 22.0 \%$ were Black/African American, 5.9\% were other races, $4.4 \%$ were two or more races, and $3.6 \%$ were unknown. The primary payors for the majority of patients were commercial insurance $(52.4 \%)$ and Medicaid (43.2\%) followed by self-pay $(3.2 \%)$ and other source (1.2\%) (Table 1). The average median household income within the patients' home zip codes was $\$ 56,242$ (standard deviation (SD): \$22,797).

The median total charge per patient was $\$ 348$ (Table 1). Overall, as age of the patient increased, total charge per patient also increased $(\mathrm{p}=0.024)$. As expected, as number of visits increased, the total charge per patient increased $(\mathrm{p}<0.001)$ (Table 2). There were also significant differences in median total charge per patient by gender $(\mathrm{p}=0.033)$, race $(\mathrm{p}<0.001)$, and primary payor $(\mathrm{p}=0.001)$ (Table 2). There was no significant difference in average median household income of the patient's zip code. Among patients with mTBIs, there were also significant differences in median total charge per patient by gender, race, and primary payor.

\section{TBI visit characteristics}

Total charges for all 5,429 TBI-related visits were $\$ 13,131,547$ (Table 3). Although unspecified head injuries

Table 2 Median total charge per pediatric patient with a principal diagnosis of traumatic brain injury at one midwest children's hospital from August 1, 2010 through July 31, 2011

\begin{tabular}{lc}
\hline & Median total charge per patient \\
\hline Gender & $\$ 375$ \\
Male & $\$ 332$ \\
Female & \\
Race & $\$ 415$ \\
White & $\$ 321$ \\
Black/African American & $\$ 327$ \\
Other & $\$ 321$ \\
Two or more races & $\$ 340$ \\
Unknown & \\
Primary Payor & $\$ 400$ \\
Commercial & $\$ 326$ \\
Medicaid & $\$ 470$ \\
Self-pay & $\$ 320$ \\
Other & \\
Number of visits & $\$ 320$ \\
1 & $\$ 864$ \\
2 & $\$ 1,231$ \\
3 & $\$ 1,808$ \\
4 & $\$ 3,531$ \\
\hline
\end{tabular}

(ICD-9-CM code 959.01) made up almost half of all TBIrelated visits $(47.4 \%)$, they accounted for only $12.6 \%$ of total charges (Table 3). Fracture of the vault or base of the skull (37.1\%) and brain injury with contusion, laceration, or hemorrhage (27.1\%) accounted for the largest proportion of total charges. While inpatient visits made up only $3.0 \%$ of all visits, $68.7 \%$ of total charges were inpatientrelated (Table 3). ED visits accounted for $16.1 \%$ of all TBIrelated charges.

The vast majority of total charges for brain injury with contusion, laceration, or hemorrhage (87.8\%), fracture of the vault or base of the skull (93.7\%), and other unqualified multiple fractures of the skull (87.8\%) visits, which are typically more severe TBIs, were inpatient-related (Figure 1). Among all concussion-related visits, the highest proportions of total charges were inpatient (31.5\%) and ED-related (34.4\%); however, a substantial proportion of total charges were associated with clinic outpatient visits (16.9\%). Among unspecified head injury-related visits (ICD-9-CM 959.01), which were all classified as mTBI-related, $18.4 \%$ of medical charges were from urgent care visits.

Although mTBIs accounted for $92.0 \%$ of all TBI-related visits, they accounted for $44.7 \%$ of all TBI-related charges (Table 3). The highest proportions of mTBI-related total charges were emergency (34.8\%), urgent care $(29.7 \%)$, and clinic outpatient-related (29.1\%). mTBIs treated in the ED had a higher median total charge per visit (median: \$356) than mTBIs treated in the urgent care (median: \$167) $(\mathrm{p}<0.001)$ or clinic outpatient setting (median: \$274) $(\mathrm{p}<0.001)$.

\section{Individuals with one visit}

The total charge for individuals with one visit was $\$ 5,836,662$ (44.4\% of total charges), and the median total charge per patient was $\$ 320$. There were a similar proportion of total charges related to unspecified head injury (23.6\%), concussion (23.2\%), brain injury with contusion, laceration, or hemorrhage (23.1\%), and fracture of the vault or base of the skull (29.5\%) (Table 4). While inpatient visits made up only $2.7 \%$ of total visits among individuals with one visit, they accounted for $55.0 \%$ of all charges (Table 4). ED visits, which made of $6.0 \%$ of all visits among this group, accounted for $28.0 \%$ of total charges.

\section{Individuals with two or more related visits}

The total charge for patients with two or more related visits was $\$ 7,219,945$ (55.0\% of total charges), and the median total charge per patient was $\$ 1,254$. The majority of charges were associated with fracture of the vault or base of the skull (43.6\%) and brain injury with contusion, laceration, or hemorrhage (30.4\%) (Table 4). While inpatient visits made up only $3.6 \%$ of total visits 
Table 3 Total charges of pediatric traumatic brain injury-related visits at one midwest children's hospital from August 1, 2010 through July 31, 2011 by diagnosis and by clinical site/setting

\begin{tabular}{|c|c|c|}
\hline & Total \# visits n (\%) & Total charges total $\$(\%)$ \\
\hline \multicolumn{3}{|l|}{ Diagnosis } \\
\hline Head injury, unspecified & $2,574(47.4 \%)$ & $\$ 1,649,203(12.6 \%)$ \\
\hline Concussion & $2,204(40.6 \%)$ & $\$ 2,498,255(19.0 \%)$ \\
\hline Brain injury with contusion, laceration, or hemorrhage & $388(7.1 \%)$ & $\$ 3,556,358(27.1 \%)$ \\
\hline Fracture of the vault or base of the skull & $186(3.4 \%)$ & $\$ 4,870,781(37.1 \%)$ \\
\hline Other and unqualified multiple fractures of the skull & $77(1.4 \%)$ & $\$ 556,949(4.2 \%)$ \\
\hline Total & $5,429(100.0 \%)^{*}$ & $\$ 13,131,547(100.0 \%)$ \\
\hline \multicolumn{3}{|l|}{ TBI severity } \\
\hline Mild TB|** & 4,992 (92.0\%) & $\$ 5,869,449(44.7 \%)$ \\
\hline Other TBI & $437(8.0 \%)$ & $\$ 7,262,098(55.3 \%)$ \\
\hline Total & $5,429(100.0 \%)^{*}$ & $\$ 13,131,547(100.0 \%)$ \\
\hline \multicolumn{3}{|l|}{ Clinical site/setting } \\
\hline Emergency & $1,776(32.7 \%)$ & $\$ 2,108,271(16.1 \%)$ \\
\hline Clinic outpatient & $1,704(31.4 \%)$ & $\$ 649,523(4.9 \%)$ \\
\hline Urgent care & $1,498(27.6 \%)$ & $\$ 397,603(3.0 \%)$ \\
\hline Diagnostic/Therapy outpatient & $242(4.5 \%)$ & $\$ 306,402(2.3 \%)$ \\
\hline Inpatient & $163(3.0 \%)$ & $\$ 9,015,770(68.7 \%)$ \\
\hline Observation & $42(0.8 \%)$ & $\$ 392,259(3.0 \%)$ \\
\hline Organ procurement & $4(0.1 \%)$ & $\$ 261,720(2.0 \%)$ \\
\hline Total & $5,429(100.0 \%)^{*}$ & $\$ 13,131,547$ (100.0\%) \\
\hline
\end{tabular}

*Totals do not sum to $100.0 \%$ due to rounding.

**The mild TBI (mTBI) category was constructed from various codes from across the five diagnosis categories.

in this group, they accounted for $80.4 \%$ of all charges. Approximately $10 \%$ of all charges among patients with two or more related visits were from clinic outpatient visits (7.4\%) and diagnostic/therapy outpatient visits $(2.7 \%)$.

\section{Discussion}

This study was the first to provide a more comprehensive estimate of the direct medical charges associated with pediatric traumatic brain injuries by analyzing total medical charges across multiple clinical settings at one large US Midwest Children's Hospital. Not surprisingly, inpatient and ED visits accounted for the highest proportion of pediatric TBI-related charges $(68.7 \%$ and $16.1 \%$, respectively); however, more than $15 \%$ of all charges were associated with visits to other clinical settings including clinic outpatient, urgent care, and diagnostic/therapy outpatient. This study demonstrates that previous studies which used ED and inpatient-based statistics alone to estimate the medical charges of pediatric TBI have undoubtedly underestimated the true medical charges associated with this serious public health issue.

As expected, children with potentially "more severe" TBIs, such as brain injury with contusion, laceration, or hemorrhage or fracture of the vault or base of the skull, were more likely to require inpatient stays and have two or more visits. As a result, these patients also had higher total medical charges. However, we also found that approximately $10 \%$ of all charges among patients with two or more related visits were from clinic outpatient visits (7.4\%) and diagnostic/therapy outpatient visits (2.7\%). This demonstrates that the bulk of the charges associated with more severe TBIs stems from the initial visit and that subsequent visits for follow up care are relatively inexpensive. Future research should determine if increasing the number of follow up visits might improve long term outcome for more severe TBI given the relatively low cost of follow up care compared to the severity of this injury and the potential for long term negative health consequences. Even among patients with more severe TBIs, failing to consider the medical charges of all visits across all clinical settings will underestimate the true cost of this important injury.

There were differences in charges by diagnosis and clinical site/setting, especially among pediatric mTBIs compared to "more severe" TBIs. Previous studies have found that mTBI-related visits may account for up to $70 \%$ to $90 \%$ of all TBIs, (Cassidy et al. 2004; Faul et al. 2010) and, in the current study, we found mTBI represented $92.0 \%$ of all TBI visits. Yet mTBIs accounted for 

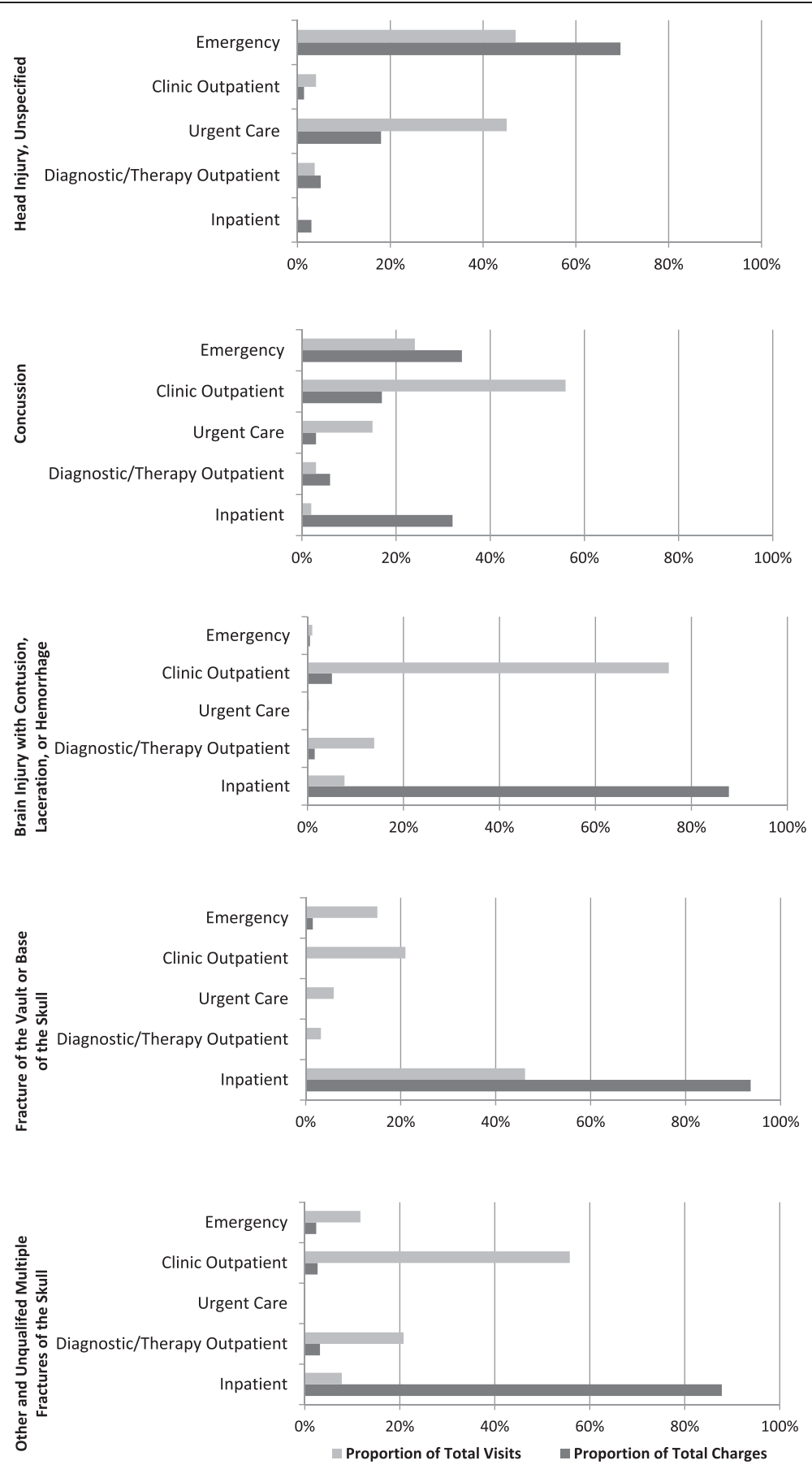

*Because observation and organ procurement visits accounted for a small proportion of total visits and charges, they were excluded from this figure.

Figure 1 Total charges of pediatric traumatic brain injury-related visits at one midwest children's hospital from August 1, 2010 through July 31, 2011 by diagnosis* and clinical site/setting.

44.7\% of all TBI-related charges. Among concussionrelated visits, the highest proportions of total charges were inpatient (31.5\%) and ED-related (34.4\%); however, a substantial proportion of total charges were associated with clinic outpatient visits (16.9\%). Similarly, $18.4 \%$ of unspecified head injury-related charges were from urgent care visits. Given the high incidence of mTBIs and the finding that mTBIs often present to clinical settings other than the ED or inpatient coupled with the substantial charges associated with mTBIs, it is important to try 
Table 4 Total charges of pediatric traumatic brain injury-related visits at one midwest children's hospital from August 1, 2010 through July 31, 2011 by number of visits per individual

\begin{tabular}{|c|c|c|}
\hline & \multicolumn{2}{|c|}{ Total charges total \$ (\%) } \\
\hline & Individuals with one visit $(n=3,185)$ & $\begin{array}{l}\text { Individuals with two or more related } \\
\text { visits }(n=740)^{*}\end{array}$ \\
\hline \multicolumn{3}{|l|}{ Diagnosis } \\
\hline Head injury, unspecified & $\$ 1,378,301(23.6 \%)$ & $\$ 232,246(3.2 \%)$ \\
\hline Concussion & $\$ 1,355,685(23.2 \%)$ & $\$ 1,122,136(15.5 \%)$ \\
\hline Brain injury with contusion, laceration, or hemorrhage & $\$ 1,348,338(23.1 \%)$ & $\$ 2,194,827(30.4 \%)$ \\
\hline Fracture of the vault or base of the skull & $\$ 1,719,853(29.5 \%)$ & $\$ 3,150,929(43.6 \%)$ \\
\hline Other and unqualified multiple fractures of the skull & $\$ 34,486(0.6 \%)$ & $\$ 519,808(7.2 \%)$ \\
\hline Total & $\$ 5,836,662(100.0 \%)$ & $\$ 7,219,945$ (100.0\%) \\
\hline \multicolumn{3}{|l|}{ TBI severity } \\
\hline Mild TB|** & $\$ 3,231,763(55.4 \%)$ & $\$ 2,562,747(35.5 \%)$ \\
\hline Other TBI & $\$ 2,604,899(44.6 \%)$ & $\$ 4,657,199(64.5 \%)$ \\
\hline Total & $\$ 5,836,662(100.0 \%)$ & $\$ 7,219,945(100.0 \%)$ \\
\hline \multicolumn{3}{|l|}{ Clinical Site/Setting } \\
\hline Emergency & $\$ 1,636,051(28.0 \%)$ & $\$ 436,763(6.0 \%)$ \\
\hline Clinic outpatient & $\$ 96,965(1.7 \%)$ & $\$ 531,581(7.4 \%)$ \\
\hline Urgent care & $\$ 329,491(5.6 \%)$ & $\$ 59,301(0.8 \%)$ \\
\hline Diagnostic/Therapy outpatient & $\$ 104,942(1.8 \%)$ & $\$ 191,765(2.7 \%)$ \\
\hline Inpatient & $\$ 3,209,383(55.0 \%)$ & $\$ 5,806,386(80.4 \%)$ \\
\hline Observation & $\$ 198,110(3.4 \%)$ & $\$ 194,149(2.7 \%)$ \\
\hline Organ procurement & $\$ 261,720(4.5 \%)$ & $\$ 0(0.0 \%)$ \\
\hline Total & $\$ 5,836,662(100.0 \%)$ & $\$ 7,219,945(100.0 \%)$ \\
\hline
\end{tabular}

*Individuals with two or more unrelated visits $(n=46)$ are excluded from this table (total charges $=\$ 74,939)$.

**The mild TBI (mTBI) category was constructed from various codes from across the five diagnosis categories.

capture as many of these injuries as possible when evaluating the true clinical, economic, and public health burden of pediatric TBIs.

We also found that mTBIs treated in the ED had a median total charge per visit that was more than two times the median total charge per visit for mTBIs treated in urgent care settings. Additional educational efforts are needed to help the public understand the signs and symptoms of concussion and the importance of seeking appropriate medical advice and proper management to avoid unnecessary and costly visits to emergency departments. However, because of the current debate surrounding the diagnostic criteria for concussion, it is difficult to determine if injuries presenting to various health care settings are truly dissimilar, or if these differences result from varying diagnostic criteria used by physicians practicing in different clinical settings. More research is needed to examine how ICD9-CM codes are being used in each type of clinical setting, particularly ICD-9-CM code 959.01 (head injury, unspecified) and other codes used for mTBI, if these codes are being used correctly, (Bazarian et al. 2006; Coronado et al. 2012b; Powell et al. 2008) and how potential clinical setting differences may affect estimates of the incidence and associated charges of TBI.

In a previous study using the same data, we found differences in patterns of pediatric TBIs by patient demographics (Collins et al: Clinical Presentation Patterns and Settings for Pediatric Traumatic Brain Injury, Currently under review at J Head Trauma Rehabil). More specifically, type of insurance, diagnosis, and number of visits varied by race. A higher proportion of white patients were diagnosed with a concussion, had commercial insurance, and had two or more related visits while a higher proportion of black/African American patients were diagnosed with an unspecified head injury, had Medicaid, and had only one visit. Because these factors were so strongly associated, we hypothesized these differences were more likely related to socioeconomic status (SES) and/or primary payor than patient's race. We found significant differences in median total charge per patient by gender, race, and primary payor. These findings suggest that children with higher SES may be receiving different care for TBIs than children with lower SES. Additional research is needed to more clearly understand how TBI visits differ by patient characteristics such as SES, if these characteristics 
influence medical decisions including when and where to seek care, and how patient characteristics and treatment decisions affect charges.

This study had several limitations. First, generalizability may be limited as data were restricted to one, large Midwest Children's Hospital. Medical charges may vary by institution or location in the US. However, multiple clinical settings in the hospital network were included, this Children's Hospital has a large geographic catchment area, and limiting this study to a single institution provided a consistency of clinical records. Second, as in all studies, we had to establish a finite study period, and we may have missed the initial injury visit for some TBI-related visits that occurred at the beginning of the study period and/or missed follow up visits that occurred after the end of the study period. However, as a relatively large number of patients who had two or more visits related to one injury event were included in the study, we are confident that those described here are representative. In addition, an academic year time period was used in an effort to capture sportsrelated initial injury visits in our study period. Third, it was not possible to determine if all medical charges were directly related to the principal diagnosis of TBI or potentially associated with concurrent injuries and/or comorbidities. Fourth, we were unable to obtain information regarding the cause of pediatric TBIs which might influence cost. Fifth, this study used total medical charges, which included all direct charges such as physician charges, pharmaceutical charges, laboratory charges, facility charges, etc. It is important to note that total medical charges may vary greatly from actual medical costs. Future studies are needed to determine how the medical cost of pediatric TBI varies across various clinical settings as well as across multiple hospitals in different regions of the country. Finally, like previous studies, the present study may have actually underestimated the true medical charges of pediatric TBIs as TBIs treated at locations outside of the hospital network would have been missed. Despite these limitations, this study is the first to capture direct medical charges of pediatric traumatic brain injuries across all health care settings associated with a large US Children's Hospital. The findings presented here should improve future knowledge of the medical cost of pediatric TBI by driving researchers to conduct future studies in samples including multiple clinical settings.

\section{Conclusions}

Pediatric TBIs present to a wide variety of clinical settings, and differences exist in total charges by diagnosis, severity of the injury, and clinical site/setting. These findings clearly demonstrate that previous research utilizing only inpatient or ED data has underestimated the charges associated with pediatric TBIs. Researchers investigating TBIs charges must be encouraged to capture data across the full spectrum of clinical care settings in order to provide both clinicians and policy makers with more complete and current information. Only when such data from multiple clinical settings are presented from large national samples will we be able to evaluate the true medical cost of pediatric TBI.

\section{Competing interests}

The authors declare that they have no competing interests.

\section{Authors' contributions}

CC conducted the data analyses, drafted the initial manuscript, revised the manuscript, and approved the final manuscript as submitted. TP, KY, RA, VC, and JG consulted on the data analyses, critically reviewed the statistical findings, reviewed and revised the manuscript, and approved the final manuscript as submitted. RDC conceptualized and designed the study, coordinated and supervised data analyses, reviewed and revised the manuscript, and approved the final manuscript as submitted.

\section{Acknowledgements}

The content of this report was funded in part by the Centers for Disease Control and Prevention (CDC) grant \# 200-2011-M-41924. The content of this report is solely the responsibility of the authors and does not necessarily represent the official views of the CDC.

\section{Author details}

${ }^{1}$ Center for Injury Research and Policy, Nationwide Children's Hospital, Columbus, OH, USA. ${ }^{2}$ Department of Pediatrics, College of Medicine, The Ohio State University, Columbus, OH, USA. ${ }^{3}$ Center for Biobehavioral Health, Nationwide Children's Hospital, Columbus, OH, USA. ${ }^{4}$ Department of Pediatrics and Family Medicine, College of Medicine, The Ohio State University, Columbus, OH, USA. ${ }^{5}$ Division of Sports Medicine Nationwide Children's Hospital, Columbus, OH, USA. ${ }^{6}$ Division of Biostatistics, College of Public Health, The Ohio State University, Columbus, OH, USA. 'Division of Unintentional Injury Prevention, National Center for Injury Prevention and Control, Centers for Disease Control and Prevention, Atlanta, GA, USA. ${ }^{8}$ Colorado School of Public Health, Epidemiology and Pediatric Injury Prevention, Education, and Research (PIPER) Program, Aurora, CO, USA.

Received: 12 December 2013 Accepted: 3 March 2014 Published: 6 May 2014

\section{References}

Anderson VA, Morse SA, Catroppa C, Haritou F, Rosenfeld JV. Thirty month outcome from early childhood head injury: a prospective analysis of neurobehavioural recovery. Brain. 2004; 127(Pt 12):2608-20. doi:10.1093/ brain/awh320.

Bazarian JJ, Veazie P, Mookerjee S, Lerner EB. Accuracy of mild traumatic brain injury case ascertainment using ICD-9 codes. Acad Emerg Med. 2006; 13(1):31-8. doi:10.1197/j.aem.2005.07.038.

Brener I, Harman JS, Kelleher KJ, Yeates KO. Medical costs of mild to moderate traumatic brain injury in children. J Head Trauma Rehabil. 2004; 19(5):405-12. doi:00001199-200409000-00005

Cassidy JD, Carroll LJ, Peloso PM, Borg J, von Holst H, Holm L, Kraus J, Coronado VG, WHO Collaborating Centre Task Force on Mild Traumatic Brain Injury. Incidence, risk factors and prevention of mild traumatic brain injury: results of the WHO collaborating centre task force on mild traumatic brain injury. J Rehabil Med. 2004; (43 Suppl):28-60.

Coronado VG, McGuire LC, Sarmiento K, Bell J, Lionbarger MR, Jones CD, Geller Al, Khoury N, Xu L. Trends in traumatic brain injury in the U.S. and the public health response: 1995-2009. J Safety Res. 2012a; 43(4):299-307.

Coronado VG, McGuire LM, Faul M, Sugerman DE, Pearson WS. Traumatic Brain Injury Epidemiology and Public Health Issues. In: Zasler ND, Katz DI, Zafonte RD, editors. Brain Injury Medicine. Principles and Practice; New York, NY 2012b.

Faul M, Xu L, Wald MM, Coronado VG. Traumatic Brain Injury in the United States: Emergency Department Visits, Hospitalizations and Deaths 2002-2006. Atlanta, GA: Centers for Disease Control and Prevention, National Center for Injury Prevention and Control; 2010. 

traumatic brain injury: acute and rehabilitation costs. Arch Phys Med Rehabil. 1993; 74(7):681-6.

Kirkwood MW, Yeates KO, Taylor HG, Randolph C, McCrea M, Anderson VA. Management of pediatric mild traumatic brain injury: a neuropsychological review from injury through recovery. Clin Neuropsychol. 2008; 22(5):769-800. doi:10.1080/13854040701543700.

Leibson CL, Brown AW, Ransom JE, Diehl NN, Perkins PK, Mandrekar J, Malec JF. Incidence of traumatic brain injury across the full disease spectrum: a population-based medical record review study. Epidemiology. 2011; 22(6):836-44. doi:10.1097/EDE.0b013e318231d535.

McCrea M, Hammeke T, Olsen G, Leo P, Guskiewicz K. Unreported concussion in high school football players: implications for prevention. Clin J Sport Med. 2004; 14(1):13-7.

Meehan WP 3rd, Mannix R. Pediatric concussions in United States emergency departments in the years 2002 to 2006. J Pediatr. 2010; 157(6):889-93. doi:10.1016/j.jpeds.2010.06.040

Moran LM, Taylor HG, Rusin J, Bangert B, Dietrich A, Nuss KE, Wright M, Minich N, Yeates KO. Quality of life in pediatric mild traumatic brain injury and its relationship to postconcussive symptoms. J Pediatr Psychol. 2012; 37 (7):736-44. DOI 10.1093/jpepsy/jsr087.

National Center for Injury Prevention and Control. Report to Congress on Mild Traumatic Brain Injury in the United States: Steps to Prevent a Serious Public Health Problem. Atlanta, GA: Centers for Disease Control and Prevention; 2003.

Orman J, Kraus J, Zaloshnja E, Miller T. Epidemiology. In: Silver J, McAllister T, Yudofsky S, editors. Textbook of Traumatic Brain Injury. Arlington, VA: American Psychiatric Publishing, Inc; 2011.

Powell JM, Ferraro JV, Dikmen SS, Temkin NR, Bell KR. Accuracy of mild traumatic brain injury diagnosis. Arch Phys Med Rehabil. 2008; 89(8):1550-5. DOI 10.1016/ j.apmr.2007.12.035

Rockhill CM, Fann JR, Fan MY, Hollingworth W, Katon WJ. Healthcare costs associated with mild traumatic brain injury and psychological distress in children and adolescents. Brain Inj. 2010; 24(9):1051-60. doi:10.3109/ 02699052.2010 .494586$.

Schneier AJ, Shields BJ, Hostetler SG, Xiang H, Smith GA. Incidence of pediatric traumatic brain injury and associated hospital resource utilization in the United States. Pediatrics. 2006; 118(2):483-92. doi:10.1542/peds.2005-2588.

Schootman M, Fuortes $L$ J. Ambulatory care for traumatic brain injuries in the US, 1995-1997. Brain Inj. 2000; 14(4):373-81.

Schwartz L, Taylor HG, Drotar D, Yeates KO, Wade SL, Stancin T. Long-term behavior problems following pediatric traumatic brain injury: prevalence, predictors, and correlates. J Pediatr Psychol. 2003; 28(4):251-63.

Shi J, Xiang H, Wheeler K, Smith GA, Stallones L, Groner J, Wang Z. Costs, mortality likelihood and outcomes of hospitalized US children with traumatic brain injuries. Brain Inj. 2009; 23(7):602-11. doi:10.1080/ 02699050903014907.

Taylor HG. Research on outcomes of pediatric traumatic brain injury: current advances and future directions. Dev Neuropsychol. 2004; 25(1-2):199-225. doi:10.1080/87565641.2004.9651928.

Thurman DJ, Alverson C, Dunn KA, Guerrero J, Sniezek JE. Traumatic brain injury in the United States: a public health perspective. J Head Trauma Rehabil. 1999; 14(6):602-15.

Yeates KO, Armstrong K, Janusz J, Taylor HG, Wade S, Stancin T, Drotar D. Long-term attention problems in children with traumatic brain injury. J Am Acad Child Adolesc Psychiatry. 2005; 44(6):574-84. doi:10.1097/01.chi.0000159947.50523.64.

Yeates KO, Kaizar E, Rusin J, Bangert B, Dietrich A, Nuss K, Wright M, Taylor HG. Reliable change in postconcussive symptoms and its functional consequences among children with mild traumatic brain injury. Arch Pediatr. 2012; 166(7):615-22. Doi:10.1001/archpediatrics.2011.1082.

doi:10.1186/2197-1714-1-13

Cite this article as: Collins et al:: Direct medical charges of pediatric traumatic brain injury in multiple clinical settings. Injury Epidemiology 2014 1:13.

\section{Submit your manuscript to a SpringerOpen ${ }^{\circ}$ journal and benefit from:}

- Convenient online submission

- Rigorous peer review

- Immediate publication on acceptance

- Open access: articles freely available online

- High visibility within the field

- Retaining the copyright to your article

Submit your next manuscript at $\gg$ springeropen.com 